\title{
ПРАВОВОЕ РЕГУЛИРОВАНИЕ ПРОЦЕССОВ ЦИФРОВИЗАЦИИ В ЭКОНОМИЧЕСКОЙ ДЕЯТЕЛЬНОСТИ ГОСУДАРСТВА И УПРАВЛЕНЧЕСКОЙ ПРАКТИКЕ СУДЕБНЫХ ОРГАНОВ, ОРГАНОВ ГОСУДАРСТВЕННОЙ ВЛАСТИ
}

\author{
(C) 2021 Кобзарь-Фролова Маргарита Николаевна \\ доктор юридических наук, профессор, \\ главный научный сотрудник сектора административного права и процесса \\ Институт государства и права РАН, Россия, Москва \\ (c) 2021 Щукина Татьяна Владимировна \\ доктор юридических наук, доцент, \\ ведущий научный сотрудник сектора административного права и процесса \\ Институт государства и права РАН, Россия, Москва
}

\begin{abstract}
Предметом настоящей статьи выступает исследование процессов правового регулирования цифровизации в экономической деятельности государства и управленческой практике судебных органов и органов государственной власти. Тема статьи отражает вопросы внедрения цифровых инструментов в практику деятельности органов исполнительной власти, судебной системы и влияния этого процесса на экономическую деятельность государства, включая уровень коррупции. Целью настоящей статьи является анализ цифровизации управленческих функций в системе государственного управления России в области воздействия на экономическую деятельность государства. Также выявление особенностей применения цифровых инструментов в европейской судебной системе, реализация концепции интернет-судов, e-justice, включая электронную отчетность в различных странах. Методологию данной работы составили сравнительный, формально-юридический, аналитический методы. Результаты работы - это формулирование влияния новых цифровых инструментов правового регулирования управленческой деятельности в органах государственной власти в условиях модернизации экономики Российской Федерации; трансформация судебной системы под влиянием процесса цифровизации и сопутствующего преодоления коррупционных рисков. Область применения результатов работы включает в себя государственную политику в области стратегического развития, управления и противодействия коррупции.
\end{abstract}

Ключевые слова: цифровое государственное управление, интернет-суды, е-јustice, коррупция

Паспортом национальной программы «Цифровая экономика Российской Федерации», утв. президиумом Совета при Президенте Российской Федерации по стратегическому развитию и национальным проектам 24 декабря 2018 г. № 16, предусмотрен федеральный проект «Цифровое государственное управление». Главной целью цифровизации в сфере государственного управления является внедрение цифровых технологий и платформенных решений в сферах государственного управления и оказания государственных услуг, в том числе в интересах населения и субъектов малого и среднего предпринимательства, включая индивидуальных предпринимателей. Интересы субъектов предпринимательской деятельности в данном федеральном проекте особо подчеркиваются, поэтому значение автоматизации экономической деятельности государства возрастает. Основны- ми направлениями цифровизации управленческой деятельности органов государственной власти до 2024 года выступают:

1) цифровая трансформация государственных (муниципальных) услуг и сервисов;

2) цифровая трансформация государственной (муниципальной) службы;

3) создание сквозной цифровой инфраструктуры и платформ;

4) разработка и внедрение национального механизма осуществления согласованной политики государств - членов Евразийского экономического союза при реализации планов в области развития цифровой экономики.

Федеральный проект предусматривает поэтапное развитие цифрового обеспечения управленческой деятельности в системе органов исполнительной власти. В 2021 году предлагается комплекс мероприятий по автоматизации раз- 
личных сфер государственного управления [1]:

a) разработать и принять федеральный закон и иные нормативные правовые акты, закрепляющие целевое состояние предоставления государственных и муниципальных услуг;

б) типизировать автоматизированное рабочее место государственного служащего на базе отечественного программного обеспечения;

в) обеспечить взаимное соответствие и нормализацию данных, используемых при межведомственном электронном взаимодействии, в информационных ресурсах государственных органов власти (в рамках формирования Национальной системы управления данными);

г) разработать и внедрить автоматизированную информационную систему проектной деятельности «Типовое облачное решение по автоматизации проектной деятельности органов государственной власти»;

д) создать единую цифровую платформу обеспечения деятельности Президента Российской Федерации, Председателя Правительства Российской Федерации, палат Федерального Coбрания, Совета Безопасности Российской Федерации, Администрации Президента Российской Федерации, Аппарата Правительства Российской Федерации и др.

Данный период связан с разработкой и внедрением более действенных платформенных решений для обеспечения:

1) качественного предоставления государственных услуг, в том числе услуг в сфере обеспечения пожарной безопасности, мониторинга безопасности объектов, техногенных и природных кризисных ситуаций, предоставляемых в интересах субъектов малого и среднего предпринимательства;

2) идентификации, включая биометрическую идентификацию, облачную квалифицированную электронную подпись, цифровые профили гражданина и юридического лица.

Касаясь цифровизации управленческой деятельности в органах государственной власти и улучшения ее воздействия, прежде всего, на экономическую функцию государства, на первоначальном этапе развитие электронного правительства и электронного государственного управления было направлено на улучшение качества предоставления государственных и муниципальных услуг. Оно сопровождалось снижением временных и стоимостных затрат граждан и юридических лиц и минимизации бумажного документооборота. Важной задачей исполнительных органов государственной власти субъектов РФ была поддержка и развитие региональных информационных систем «Портал государственных и муниципальных услуг» и информационных порталов исполнительных органов государственной власти субъектов РФ. Информационные системы способствовали развитию сервисов для упрощения процедур взаимодействия общества и государства с использованием информационных технологий. Добавим, что для проведения закупки с участием субъектов малого и среднего предпринимательства закреплялись дополнительные требования к электронным площадкам проведения конкурентной закупки товаров, работ, услуг для обеспечения государственных и муниципальных нужд [2]. Широко начал применяться в процессе цифровизации управления такой инструмент гражданского оборота, как электронная подпись. Более прозрачным и объективным стал процесс предоставления информации о деятельности органов государственной власти на официальных сайтах.

В настоящее время полностью вся система органов публичной власти стоит перед процедурой не обычного перевода бумажного документооборота в электронный формат, а перед форматированием функций органов государственной власти с помощью цифровых технологий. Она связана с трансформацией компетенции органов исполнительной власти, реализацией полномочий органов власти и соответственно части функций управления не физическим лицом (госслужащим) при помощи его интеллекта, навыков и привычного для нас труда, а цифровыми инструментами в форме виртуального исполнения полномочий.

Внедрение цифровых инструментов распространяется и в судебной системе. Причем, цифровизация активно влияет на снижение коррупционных рисков в управленческой деятельности. Развитие судебной системы и совершенствование мероприятий по противодействию коррупции, как правило, дополняют друг друга и едины в экосистеме демократического государства. Например, модернизация судебных систем государств - членов ЕС, которые в недавнем прошлом вошли в эту государственноправовую коллаборацию, проходит с чередующимися успехами и неудачами в области противодействия коррупции. 
Рассмотрим развитие судебной системы Румынии, которая предполагает внедрение комплекса мероприятий по предупреждению и пресечению коррупционных проявлений. Данный анализ проведен на основании Report from the Commission to the European Parliament and the Council on Progress in Romania under the Cooperation and Verification Mechanism [3]. Одним из основных направлений совершенствования судебной системы выступает укрепление независимости судебной системы страны. Это заключается в последовательном решении проблемы устранения рисков политического вмешательства в процесс назначения на высшие должности, включая должности судей. Например, назначение главного прокурора Управления по расследованию организованной преступности и терроризма. Риски устраняются путём формирования прозрачных и основанных на заслугах процедур отбора. Процедура отбора включает сильный политический элемент с точки зрения роли, которую она отводит в этом процессе министру юстиции. Особое внимание уделяется защите независимости правосудия и профессиональной репутации, которые могут быть затронуты СМИ путём предъявления ложных обвинений в коррупции и соответствующей резкой критики судей. В целях борьбы с указанными явлениями в Румынии создана инспекция для защиты независимости правосудия и профессиональной репутации, независимости и беспристрастности мировых судей.

Следующее направление - это усиление эффективности, подотчетности и качества правосудия. Вопрос относительно улучшения подотчетности правосудия уже в ключе технологий e-justice будет рассмотрен ниже. Главными проблемами, требующими решения в судебной системе Румынии, стали моменты, касающиеся сущности обучения судебных секретарей (укрепление профессионализма), поддержка профессиональных Институтов подготовки судебных кадров (Национальна школа секретарей), увеличения количества должностей судебных секретарей и увеличение числа судебных и модернизации ИТ-оборудования судов и Судебной инспекции. Все это увязывается с определённой мерой профилактики коррупции в судебной системе. Решение проблемных вопросов в румынской судебной системе, равно как и в некоторых других европейских судебных системах, касается оптимизации судебной нагрузки. Нагруз- ка - это повторяющаяся проблема в судебной системе, так как влияет на качество судебных решений и удобство судебной системы. Прежде всего, решение загруженности судей путём устранения дублирования при исполнении решений. В последнее время в Румынии гражданские суды были освобождены порядка от 300000 дел. Это было связано с оптимизацией распределения полномочий между судьями и судебными секретарями, устранением параллелизма между судами и Прокуратурой, внедрением мобильных судов.

Необходимо отметить роль Судебной инспекции в этом процессе, которая усилила качество применения мер ответственности к судьям за должностные проступки и дисциплинарные проступки. Судебная инспекция зарекомендовала себя как ключевой орган по расследованию дисциплинарных нарушений. Деятельность в Румынии Национального агентства по неподкупности и Национального совета по неподкупности обеспечило доверие населения к правительственным учреждениям и судебной системе. Особенно реализация этим органом процедуры выявления несовместимости и конфликта интересов.

В судебной системе Болгарии также действует Высший судебный совет, который обладает широкими полномочиями по управлению и организации болгарской судебной системы. Данный анализ проведен на основании Report from the Commission to the European Parliament and the Council on Progress in Bulgaria under the Cooperation and Verification Mechanism [4].

В качестве проблемы, требующей системного решения также выделяется усиление прозрачности и объективности при назначении судей путём совершенствования процедуры голосования в Совете, в том числе посредством «один судья - один голос» для судебной квоты членов Совета. Основой прозрачности процедуры назначения выделяют оценку честности и заслуг кандидата на должность судьи. Ключевым действующим лицом в продвижении честности и эффективности в судебной системе всегда была Судебная инспекция. Вопросом реализации профилактики коррупции выступает тщательный и независимый анализ системы случайного распределения дел, чтобы административные руководители судов несли полную ответственность за любое решение об отказе от случайного распределения. 
В этой процедуре обеспечение случайности распределения дел формирует система электронного правосудия. Электронная платформа, обеспечивающая случайность распределения дел между судьями, обязательно должна подвергаться внешней экспертизе в области ИТ-безопасности с помощью соответствующего тестирования. Проблемой внедрения цифровых инструментов в деятельность судов, которая повторяется в деятельности европейских судебных систем, является сложность в формировании методологии оценки загруженности мировых судей и судебных органов. Установление оптимальных правил измерения и распределения рабочей нагрузки с учетом сложности, а также масштаба дел позволит эффективно применять цифровые платформы по случайному распределению дел. В настоящее время на европейском уровне отличия в рабочей нагрузке судей рассматриваются как существенная причина неэффективности судебной системы и ее коррупциогенности. Надежная методология является основой для оценки оправданности ликвидации судов с очень небольшой рабочей нагрузкой (или введения системы «мобильных судов») с одновременным перераспределением ресурсов в пользу других перегруженных судов.

Ключевыми факторами профилактики коррупции в судебной системе являются формы оценки и продвижения по службе, а также качество обучения. Так, Национальный институт юстиции в Болгарии продолжает развивать свой креативный формат по обучению судей. Нужно обратить внимание на усиление роли прокуратуры Болгарии в реализации мер по противодействию коррупции. Прокуратура Болгарии создала небольшую специализированную структуру, в состав которой входят прокуроры и следователи Государственного агентства национальной безопасности для более эффективного расследования случаев коррупции в государственных органах.

На основании вышесказанного отметим, что ключевыми направлениями в реализации мер по противодействию коррупции в судебной системе выступают:

1) обеспечение независимости, подотчетности и неподкупности судебной власти (внедрение прозрачной процедуры назначения судей, оценка их честности и заслуг, оптимизация структуры судов; решение проблем загруженности судей и прозрачного и беспристрастного распределения дел; создание Судебных Инспекций, наделённых полномочиями по расследованию коррупционных правонарушений в судебной системе; деятельность самостоятельных агентств и советов по неподкупности, занимающихся расследованием конфликта интересов);

2) усиление роли прокуратуры в реализации мер по противодействию коррупции в судебной системе и государственной администрации;

3) внедрение электронного правосудия как средства улучшения судебного процесса.

Коснёмся вопроса внедрения е-justice в европейской судебной системе. В Европейском Союзе одним из приоритетных направлений электронного правосудия выступает создание мощных цифровых платформ для участников судебного процесса. Рассмотрим европейский портал электронного правосудия. Он задуман как будущий электронный универсальный marketplace в области правосудия, и предназначен для предоставления информации о системах правосудия и улучшения доступа к правосудию во всем ЕС на 23 языках. Переход на новую версию европейского судебного портала произошел 15 июня 2021 года (веб-сайт: https://ejustice.europa.eu).

Интересны сами по себе разделы портала и их содержательное наполнение. Раздел «Family matters \& inheritance» включает в себя информацию о наследовании, статусе имущества, нажитого в браке и гражданском партнерстве; процедура развода, родительская ответственность и др.

Раздел «Taking legal action» включает в себя подробную информацию о процессе подачи иска в ЕС. Клиентам предлагается информация о медиации как альтернативном методе разрешения споров (ADR); возможность создания заполненной PDF-формы процессуального документа для отправки в суд или загрузка пустой редактируемой PDF-формы документа. Присутствует общая информация о различиях в судебных системах стран ЕС; информация о получении бесплатной юридической помощи в гражданском и уголовном процессе; правила обращения в суд и др.

Раздел «Registers - business, insolvency \& land» - это информация о реестрах предприятий, земли и банкротства на уровне ЕС и на национальном уровне. Например, предлагается доступ к информации о земельных кадастрах в 
государствах-членах, рекламируется широкий спектр услуг, которые могут отличаться в этих государствах; о действиях, необходимых для улучшения координации между земельными кадастрами на европейском уровне.

Раздел «Money/monetary claims», элесь представлена информация о законодательстве, процедурах, сборах и формах по финансовым вопросам. Раздел «Your rights» фиксирует собой различные информационные страницы, касающиеся прав граждан ЕС. Раздел «Court procedures» включае в себя информацию о судопроизводстве по гражданским и уголовным делам. Раздел «Legislation and case law» - это информация о законодательстве и прецедентном праве, применимых к гражданам ЕС, и о судебных решениях. Раздел «Trainings, judicial networks and agencies» содержит информацию о существующем судебном обучении и профессиональных юридических организациях.

Подобные цифровые платформы и цифровые решения для клиентов должны быть удобными, и в тоже время отслеживаемыми и нейтральными.

Вторым направлением в обеспечении эффективности судебной системы с помощью электронного правосудия является разработка и внедрения в деятельность судов новых цифровых технологий. Например, в Португалии приоритетами в правосудии признаются внедрение новых технологий: искусственного интеллекта, дополненной реальности, блокчейна и Интернетом вещей. В апреле - июне 2021 года [5] активно судейским сообществом обсуждались вопросы использования искусственного интеллекта для реализации анонимности и псевдонимизации судебных решений. Это - публикация практик судебных решений, в том числе онлайнпубликации, предоставление судебных решений в виде открытых данных, подходы к защите персональных данных, методы анонимизации и псевдонимизации судебных решений; решения, доступные на рынке. Помимо указанного, дискутируется вопрос о трансформации человеческого голоса в текст и наоборот, а также применение данного формата в правосудии.

Для улучшения деятельности судебных систем стран ЕС разработана цифровая платформa e-CODEX. Электронное правосудие является центральным элементом европейской стратегии и деятельности, а е-CODEX создан как эталонный проект для оцифровки трансграничного сотрудничества судебных органов.

Электронная отчетность в судебной системе как элемент e-justice. Понимание электронной отчетности в судебной системе варьируется от компьютерной транскрипции до цифровых аудиосистем и аудиовизуальных (A/V) записей. «В Румынии, например, для усиления эффективности и подотчетности в судах была внедрена система аудиозаписей. Судебная Инспекция использует аудиозаписи для исследования вопроса о коррупции и ненадлежащем поведении судей. Аудио и видео записи осуществляются в Хорватии, необходимая аппаратура установлена в 90 залах судебных заседаний. Стороны могут запросить записи по решению председательствующего» [6].

«Для преобразования аудио или видеозаписи в текст (цифровую транскрипцию) в Сингапуре Верховный Суд использует цифровую транскрипцию, которая делает аудиозаписи, которые затем преобразуются в расшифровки стенограмм в реальном времени. Эти записи могут быть синхронизированы с комментариями, сделанными судьями во время слушаний, поэтому судья может одновременно воспроизводить слушание и видеть соответствующие записи. Запрашивающие стороны платят поставщику услуг за услуги транскрипции» [7].

Кения применяет подобную цифровую транскрипцию как пилотный проект в собственной судебной системе.

Следующим направлением электронной юстиции выступает создание и деятельность интернет-судов. «В Китае интернет-суды проводят свои разбирательства в режиме онлайн и занимаются гражданскими спорами в режиме онлайн. Эти суды впервые возникли в 2017 году как побочная ветвь проекта «Интеллектуального суда» SPC, и они объединяют последние разработки в этом проекте с традиционными операциями в зале суда. SPC учредил первый интернет-суд в городе Ханчжоу. Это помещение, оборудование многофункциональным веб-сайтом в качестве онлайн-платформы, залами судебных заседаний с большими экранами и штатом судей в количестве 20 человек. Опубликованные записи показывают, что средняя продолжительность этих онлайн-заседаний составляла 28 минут, а средний период обработки от подачи онлайн-жалобы о прекращении дела в Интернет-суд Ханчжоу составила 38 дней» [8].

Индия делает акцент на усилении роли об- 
щественных организаций в борьбе с коррупцией как в судебной системе, так и государственном управлении. «Среди известных организаций Bharat Swabhiman Trust, основанный Рамдевым, в течение десяти лет ведет кампанию против черных денег и коррупции. Ассоциация социальной прозрачности, прав и действий (ASTRA) - это неправительственная организация, деятельность которой направлена на борьбу с коррупцией в Карнатаке. Хотя в Индии действует законодательство о противодействии коррупции: Закон о судебных стандартах и ответственности был принят Лок Сабхой (нижней палатой парламента) 29 марта 2012 года, Закон о предотвращении коррупции 1988 г., Закон о сделках Бенами (запрет) 1988 г., Закон о предотвращении отмывания денег, 2002 г., Закон о праве на информацию, 2005 г., г., Закон о защите осведомителей, 2011 г. и другие законодательные акты, но особого эффекта в процессе их реализации не наблюдается» [9].

Думается, что разумное развитие е-justice в Индии, Кении и других государствах позволит сделать работу органов государственной власти и судов более прозрачными и эффективными для общества.

\section{Библиографический список}

1. Паспорт национальной программы «Цифровая экономика Российской Федерации», утв. президиумом Совета при Президенте Российской Федерации по стратегическому развитию и национальным проектам 24 декабря 2018 г. № 16. Режим доступа: https://internet.garant.ru/\#/document/72190282/paragraph/15 50/ doclist/12498/showentries/false/

2. Об утверждении дополнительных требований к функционированию электронной площадки для целей осуществления конкурентной закупки с участием субъектов малого и среднего предпринимательства: постановление Правительства РФ от 8 июня 2018 г. N 657 // Собр. законодательства Рос. Федерации. 2018. № 26. Ст. 3844 .

3. Report from the Commission to the European Parliament and the Council on Progress in Romania under the Cooperation and Verification Mechanism. Режим доступа: https://eur-lex.europa.eu/legal-content/EN/ TXT/?uri=celex\%3A52015DC 0035

4. Report from the Commission to the European Parliament and the Council on Progress in Bulgaria under the Cooperation and Verification Mechanism. Режим доступа: https://eur-lex.europa.eu/legal-content/EN/ TXT/?uri=celex\%3A52015DC 0036

5. High Level Conference For a people-centered e-Justice April 26 and 27, 2021. Режим доступа: https://еu2021. justica.gov.pt/

6. Джорджия Харли, Агнес Саид Электронное правосудие: улучшает ли электронное судопроизводство работу суда? Режим доступа: https://blogs. worldbank.org/europeandcentralasia/e-justice-does-electronic-courtreporting-improve-court-performance

7. Джорджия Харли, Агнес Саид Электронное правосудие: улучшает ли электронное судопроизводство работу суда? Режим доступа: https://blogs. worldbank.org/europeandcentralasia/e-justice-does-electronic-courtreporting-impro ve-court-performance

8. Zhuhao Wang China's E-Justice Revolution, 105, JUDICATURE 36 (Spring 2021). Режим доступа: https://www. researchgate.net/publication/342666867_China\%27s_E-Justice_Revolution

9. Beniwal, V.S. and Sikka, KapiL (2017) «E-Governance in India: Prospects And Challenges», International Journal of Computer and Communication Technology: Vol. 8: Iss. 2 Article 1. 